\title{
Representation(s) of Developed and Developing Countries in Newspapers' Coverage of Climate Conferences: A Critical Discourse Analysis
}

\author{
Lưu Thị Kim Nhung ${ }^{1}$ \\ ${ }^{1}$ Faculty of English, Hanoi National University of Education, Hanoi, Vietnam \\ Correspondence: Luu Thi Kim Nhung, Faculty of English, Building D3, Hanoi National University of Education, \\ 136 Xuan Thuy, Cau Giay, Hanoi, Vietnam. Tel: 84-912-391-458. E-mail: nhungltk172@gmail.com
}

Received: October 4, 2017 Accepted: November 1, 2017 Online Published: December 23, 2017

doi:10.5539/ijel.v8n2p35 URL: http://doi.org/10.5539/ijel.v8n2p35

\begin{abstract}
This study critically analysed how developed and developing countries were represented in The Independent and The New York Times' coverage of the Conferences of the Parties to the UNFCCC between 2004 and 2013. The method of analysis was a qualitative critical discourse analysis in accordance with Fairclough's (1989) framework with the support of corpus techniques.

The research findings showed that there were distinct responsibilities for climate change ascribed to the developed and the developing countries. While the developed countries were represented as being reluctant and indifferent towards their responsibility, the developing countries tended to depend on the developed countries' support in solving their climate-related problems. During the study period, therefore, no consensus could be reached on a common framework for climate change. The linguistic features of lexical choice, passivisation, nominalisation, modality and metaphor were found ideologically employed in the newspapers' representations of the countries. Additionally, the ideologies and their linguistic manifestations were influenced by the media's discursive practices and the wider social context.
\end{abstract}

Keywords: critical discourse analysis, corpus, climate change, developed countries, developing countries

\section{Introduction}

Ever since climate change officially emerged on the world's agenda at the Earth Summit in 1992, twenty-two Conferences of the Parties (COPs) to the United Nations Framework Convention on Climate Change (UNFCCC) have been organised, through which participating countries are believed to negotiate and develop a single global framework for every country to take their part in internationally cooperative efforts to tackle climate-related problems. Until now, however, the Kyoto Protocol (Note 1) is still considered the only single global climate treaty though it is perceived with quite different attitudes. Developed countries seek to replace the protocol because they see their development undermined by committing to its principle of "common but differentiated responsibilities" (United Nations, 1998) while developing countries defend the benefits they have with the protocol. So far, the conflict between countries' economic concerns and immediate needs for climate safety has made it hardly possible for the parties at the COPs to reach a consensus. The incapability of governments to forge effective progress has historically been attributed to the divide and conflict between the developed and developing countries (Parks \& Roberts, 2010) due to their positions on who should pay and how much should be paid for climate change (Penetrante, 2010).

Underlying such conflicting obligations and interests regarding climate change, there must be ideologies about countries' responsibilities and particular linguistic features in the media to represent countries' responsibilities, attitudes and behaviours. Despite the body of existing literature focusing on the rhetorical devices, discourse strategies, metaphors, and other aspects of discourse on climate change (e.g., Boykoff \& Boykoff, 2004; Boykoff \& Robers, 2007; Carvalho, 2005, 2007; Fløttum \& Gjerstad, 2017; Grundmann \& Krishnamurthy, 2010; Moser \& Dilling, 2007; Nerlich \& Koteyko, 2011; Ukonu, Akpan, \& Anorue, 2013; Wodak \& Meyer, 2012), almost no research has analysed the linguistic realisations of the ideologies of developed and developing countries' responsibilities for climate change as they were (re)constructed in the media's coverage of the COPs. 
This study, therefore, aimed to (1) analyse the linguistic features in the media discourse and decode the ideologies of developed and developing countries' responsibilities for climate change conveyed via the discourse; and (2) interpret and explain the ideologies of these responsibilities in light of the social, political, and historical context embedding the discourse. It was set out to answer these research questions:

- What are the ideologies about the developed and developing countries' responsibilities for climate change?

- How are these ideologies linguistically manifested via the newspapers under study?

\section{Literature Review}

\subsection{Conceptual and Methodological Considerations}

With its interest in the relationship between language and power, critical discourse analysis (CDA) studies "the way social power abuse, dominance, and inequality are enacted, reproduced, and resisted by text and talk in the social and political context" (Van Dijk, 2001, p. 352) in order to decode the ideology embedded in the discourse. One of the leading approaches to CDA is the Dialectical-Relational Approach (Fairclough, 1989, 2015) which aims to solve social problems via its three-dimensional analysis: textual, discursive and social (see section 3.2).

In CDA, text is considered "linguistic/semiotic elements of social events" (Fairclough, 2005, p. 916). The newspapers' articles (texts) which covered the COPs are the linguistic realisation of the issues at the COPs. Discourse is a form of "social practice" (Fairclough \& Wodak, 1997, p. 258), "used to mean something and to do something" (Richardson, 2007, p. 24). Ideology is the "political or social systems of ideas, values of groups (van Dijk, 1998, p. 3), "work[ing] through disguising its nature, pretending to be what it isn't" (Fairclough, 2015, pp. 113-114). Therefore, in order to decode the ideologies about the developed and developing countries' responsibilities for climate change from the language in the newspaper discourse under study, we assume that the sample newspaper articles carry these ideologies and the detection of the ideologies commences with the textual level of analysis. We expect to uncover the ideologies about countries' responsibilities for climate change hidden in the texts and to interpret the ideologies via the discursive practices of the two newspapers under study as embedded in the contextual background of the COPs.

In recent decades, the employment of corpus tools in CDA has allowed researchers to elicit specific language features within their contexts of use in a quicker and more accurate manner. These elicitations of linguistic features with corpus techniques are helpful in that they may "stimulate new ideas which might lead to new directions in investigation and analysis" (Fairclough, 2015, p. 21). In this study, corpus techniques were employed in the first phase of data analysis to provide an overview of the fairly large data (see section 3.2).

\subsection{Previous Studies}

Numerous studies have been conducted on the media discourse of global warming and/or climate change. The content analyses by McComas \& Shanahan (1999), Dispensa \& Brulle (2003); the frame analyses by Trumbo (1996), Weingart, Engels, \& Pansgrau (2000), Carvalho \& Burgess (2005), Carvalho (2007), Boykoff (2008); the discourse analyses by Dryzek (2005), Gillard (2016); the narrative analysis by Fløttum \& Gjerstad (2017); the representation analyses by Boykoff (2008), Carvalho \& Pereira (2008), Wodak \& Meyer (2012); the metaphor analyses by Moser \& Dilling (2007), Nerlich, Evans, \& Koteyko (2011); the quantitative studies by Boykoff \& Boykoff (2004), the corpus-assisted CDA studies by Caillaud, Kalampalikis, \& Flick (2012), Grundmann \& Krishnamurthy (2010), Wang (2009), to name but a few, have advanced our knowledge about the diversity in research approaches as well as the variety of issues related to climate change. However, to our best knowledge, there is hardly any research into how the ideologies about developed and developing countries' responsibilities for climate change are constructed in the media coverage of the international climate conferences. This study, therefore, sought to contribute to the existing literature by analysing these ideologies as conveyed via the newspapers' coverage of the COPs.

\section{Research Method}

\subsection{Data}

Since they are a good site for ideology (Chouliaraki, 1999) and can exert a pervasive influence on social reproduction (Fairclough, 1989), the media, particularly The Independent and The New York Times newspapers, were chosen as the source of data. As the national news leaders and broadsheet newspapers of the UK and US, their language is viewed as a neutral mediator of reality. Moreover, this study focused on the newspapers' coverage of the COPs rather than that of all climate change events because the COP is the UNFCCC's supreme decision-making body and attracts large attention from the media to provide sufficient data. Two study corpora 
were subsequently developed from 779 articles (with 766,305 running words) published by the two newspapers within one week before, during, and one week after the COPs between 2004 and 2013. Each sample article mentions the key words "climate change" at least once (see Boykoff \& Roberts, 2007; Carvalho, 2007).

\subsection{Analytical Framework}

The data were first approached through our frequency and collocation analysis with the software Wordsmith Tools 6.0 (Scott, 2012) and then our manual concordance analysis.

First, frequency analysis helped verify the most frequently occurring countries in the corpora as developed, developing, rich, and poor countries. These are termed the nodewords, namely developed and developing countries. Second, collocation analysis examined the adjectival, nominal, verbal, and adverbial collocates of the nodewords. In so doing, the corpus tools provided an overall look at the data to identify the focus of the manual concordance analysis.

Then, Fairclough's $(1989,2015)$ analytical framework was adopted. The three levels of textual, discursive and social analysis formed a unified whole in our analysis. At the level of textual analysis, the frequently used linguistic features in the newspapers' construction of developed and developing countries were analysed, including lexical choice, metaphor, passivisation, nominalisation, and modality. The lexical choices were analysed for both the denoted and connoted meanings in the discourse. The conceptual metaphors were studied with their "ideological attachments" (Fairclough, 1989, p. 119). Passivisation and nominalisation were examined as they are supposed to remove important political implications (Fairclough, 2000). For instance, the agentless passivisation in "They insisted on more help given to poor countries." veils the help-giver while poor countries are passivised as the beneficiary of more help. Modalities, such as must in "Fast-growing countries must share the burden of climate finance." signal obligation, which is a matter of ideological interest (Fairclough, 1989).

At the level of discursive analysis, we examined the newspapers' political commitments, the media's view of the relation between themselves and the audience, their news agenda (Richardson, 2007). The Independent is considered centrist and commits to both economically neoliberal and social democratic ideology (Carvalho \& Burguess, 2005). The New York Times is liberal capitalist (Gentzkow \& Shapiro, 2010), adheres to balanced reporting and emphasises the conflict between the responsibility for climate change and economic concerns.

At the level of social analysis, the wider social context including an overview of climate change, the historical background to the relations between developed and developing countries, the world's economies, the countries' policies on climate change, etc. were used to explain the ideologies and their linguistic manifestations.

\section{Analysis and Discussion}

Basically, two major ideologies were discerned in The Independent and The New York Times' coverage of the COPs: (1) the developed countries' responsibility for climate change and their attitudes towards such responsibility, and (2) the developing countries' responsibility for climate change and their attitudes towards it. These ideologies were realised by the linguistic features identified in the study's analytical framework, then interpreted and explained via the discursive practices and social context.

\subsection{The Developed Countries}

\subsubsection{The Developed Countries' Responsibility for Climate Change}

It is found in The Independent corpus that the rich developed countries' responsibility for climate change is diachronically prevalent. In 2005 , the Kyoto protocol is personified to "commit 40 rich nations to cutting their carbon emissions." In 2006, the developed countries' responsibility is to lead; for instance:

Excerpt 1: Britain, as the first industrialising country, contributed disproportionately to existing $\mathrm{CO}_{2}$ concentrations and therefore has a moral responsibility to take the lead with other rich countries before expecting developing countries to do their share. (The Independent, 15 November 2006; emphasis added)

The Independent's lexical choice of "to take the lead" represents the developed countries in the expected leadership role in combatting climate change. In other articles, its lexical choices also focus on the idea that developed countries are responsible for the current climate problems. For example: 


\begin{tabular}{ll}
\hline Lexical choice & Date of issue \\
\hline - make commitments to cut emissions & 06 December 2009 \\
- take legally binding actions to cut their carbon emissions & 20 December 2009 \\
- contributing the most to climate change & 26 November 2007 \\
- $[$ being] responsible for the majority of emissions & 26 November 2007 \\
- $[$ being] most of the excess CO2 currently in the atmosphere & 10 December 2008 \\
- contributed the lion's share of emissions in the past & 06 December 2009 \\
- $[$ being] the biggest CO2 emitters in the world by far & 20 December 2009 \\
- $[$ contributing] more than 70 per cent of all man-made carbon in the atmosphere & 15 November 2006 \\
\hline
\end{tabular}

The newspaper's tendency of advocating that the developed countries take action against climate change due to their historical contribution to the problem is consistent with previous studies (Carvalho \& Burgess, 2005; Carvalho, 2007).

However, this argument is adduced only between 2006 and 2009. It can be deduced that in the later years in our study, The Independent becomes less outspoken about the developed countries' role in the fight against climate change. This shift in the newspaper's ideology reflects its political commitment and the socio-political context that embeds the language and the discursive practice. The Independent's ideological lines often sway between the two poles: (1) a neoliberal ideology which frames climate change as a global threat and requires every country to share the burden of responsibility for fighting against it; and (2) a social democratic ideology with a precautionary approach to climate change, global equity and socially shared responsibility (Carvalho, 2005, 2007; Carvalho \& Burgess, 2005). In terms of socio-political context, there have been changes in the position of the UK's Prime Minister through this study period. In the first three years (2004-2007) of the study, the Prime Minister was Tony Blair from the Labour Party. The next three years (2007-2010) was under Prime Minister Gordon Brown who issued the first ever Climate Change Act in 2008. Since 2010, under the governance of the Prime Minister David Cameron, the newspaper seems to call for the developing countries to take responsibility alongside the developed ones.

In a similar vein, the rich developed world's responsibility for climate change is represented in most of The New York Times' concordances of "rich countries." In accordance with the newspaper's adherence to balanced reporting, which presents both sides of a story, this responsibility is voiced from both within the rich developed world and the outer side of it, that is, the developing and poor world. In all of the excerpts that report the rich world's voices, rich countries are passivised after the verbs "press," "calls" (which manifest some sort of order or pressure on the rich countries to do things), the nouns "promise" and "obligations" (i.e., moral or legal requirements, duties). In these passivised instances, the developed countries' responsibility includes "committing to spend more on providing technologies to developing countries" (2007), "receiv[ing] carbon credits for investing in sustainable projects in developing countries" (2007), "commit[ting] themselves to sharp reductions in greenhouse-gas emissions" (2009), "help[ing] poor countries to cope with a problem they had no part in creating" (2011), and "mobiliz[ing] \$100 billion a year by 2020 to help more vulnerable states adapt to climate change" (2012). Such responsibility is due to their historical contribution of $\mathrm{CO}_{2}$ into the atmosphere, which is especially emphasised with the hyperbole "the bulk of the emissions in the atmosphere" (The New York Times, 2009; emphasis added). In sum, the developed nations are responsible for reducing their greenhouse gases emissions at home and aiding poor developing countries via technology, investment, and money.

In The New York Times' concordances representing the poor developing world's voices, the rich countries are also more often passivised, but the lexical choices are different from those representing the rich world' voices. The verbal processes of "insist," "says," "want," "demand," "argued," "pressing for," and even "challenged" are articulated by the poor developing world in their communication with the rich world. For example:

Excerpt 2: Poor nations here are pressing for a new effort that goes beyond reducing emissions and adapting to a changing climate. (The New York Times, 16 November 2013; emphasis added)

These verbs do not manifest the kind of order, but express the poor developing countries' urgent request that the rich countries be responsible for climate change. In addition, the modal verbs "must," "should," and "need" modify the verbal phrases that express what the rich countries are demanded to do by the poor developing ones, such as "take the lead," "take the initiative" (2004), "bear responsibility for the increase in global carbon dioxide levels" (2006), "take the first step" (2007), "commit to far deeper emissions cuts than they already have, and provide them with cash and technology" (2009), "create a huge pool of money to help poorer countries recover" (2013). Moreover, in The New York Times' concordances of "developing countries," the developed world is represented with "should reduce emissions faster," "compensate developing countries," "support developing 
countries," "give help to developing countries," and "disburse large sums in annual aid for climate defence in developing nations."

In addition, the developing countries are mostly passivised in The New York Times as those who are affected by climate change and as the beneficiary of the climate aid, such as "developing countries could be compensated," "support developing countries," "more help given to developing countries," "annual aid for climate defence in developing nations," "bear to those in the developing world." Through these lexical choices, modality, and passivisation, the developing countries are constructed as constantly and unequivocally demanding that the developed countries take action and provide money.

The plausible arguments for the developed countries to take responsibility for climate change problems can be traced back to the socio-economic and historical context of the North-South or developed-developing divide (Penetrante, 2010). Actually, the dichotomy between developed and developing countries at the COPs is clearly identified in the UNFCCC. With the division of Parties to the UNFCCC into Annex I and non-Annex I countries, this policy framework reflects upon the historical North-South divide and forms a new conflict between the developed and developing countries as the former are held responsible for causing climate change due to the large amount of $\mathrm{CO}_{2}$ emitted during their industrial revolution. Hence, under the Kyoto Protocol, the framework ascribes the quantified emission reduction commitments to the developed countries while nothing to the developing ones.

In brief, the rich developed countries' responsibility for climate problems includes to further reduce their carbon emissions and to provide the poor developing countries with financial and technological aid. However, the developed nations want such responsibility to be shared by the developing countries as well. That is why their responsibility for climate change is not represented as reality, but still something possible and desirable.

\subsubsection{The Developed Countries' Responsibility for Climate Change Is a Possibility, Not a Reality}

Over the ten-year period of The Independent's coverage of the COPs in this study, the developed countries are continuously represented with such modal verbs as "must," "need to," "should," even a combination of auxiliary verbs with the quasi-modal "have to" in "will/would have to" and "may have to." These modalities complement the material processes of "lead the way," "work with developing countries to find an equitable way forward," "reduce their emissions," "act first," "make greater efforts to cut emissions," "provide funds for developing countries to adapt to climate change." Specifically, the use of the modal verb "should" implies that "provid[ing] funds for developing countries" is merely a desired action, i.e., something that is said, not done yet. In addition, when money is mentioned, the modal "would" is deployed to indicate the possibility of the money delivery, i.e., not the real delivery of money. The excerpts below exemplify this category.

Excerpt 3: United Nations officials said part of the financing would come from developed countries through aid and other financing would come from carbon credits traded under the Kyoto pact. (The New York Times, 15 December 2007; emphasis added)

Excerpt 4: In the meantime, he [representative of a nonprofit advocacy group] said, the United States and other developed countries "need to take the lead." (The New York Times, 16 December 2007; emphasis added)

It is noteworthy, though, while some occurrences of "should" necessarily indicate desirability, some may signal obligation alongside with the obligatory "must" and "have to." Besides, obligation modality is manifested through the adjective "essential" in "it is essential that governments in developed nations recognize that tackling climate change is not just a moral responsibility they bear to those in the developing world but an essential part of their national interest" (The Independent, 05 December 2012). These modalities convey the desirability that the developed countries take responsibility for climate-related problems. The use of such deontic modality in discourse does have an epistemic function (Lillian, 2008). By employing the deontic modals signifying desirability and obligation, The Independent is evidently seeking to persuade, even manipulate, its readers to adopt and pursue the agenda. By "manipulate," we refer to van Dijk's (1998) notion of manipulation, that is, using power to persuade the audience to believe in things that are in the best interests of the manipulator and his/her group but not of the manipulated.

Furthermore, nominalisations are employed by the media; for instance, "demand for a giant new insurance scheme funded by developed countries," "need for stronger action by developed countries," and "pressure on the leaders of developed nations to embrace tougher reductions of carbon emissions and to do more to alleviate those countries most vulnerable to the effects of climate change" (The New York Times, 08 December 2007) in which developed countries are all obfuscated. This integration of syntactic structures blurs the role that the developing 
countries have to play in financing climate-related issues. In this way, the responsibility is represented as something untaken.

Through the modalities modifying what the developed countries are supposed to do, the developed world is represented as not yet to take the desired responsibility whereas the developing world is represented as not yet to receive the aid from the developed one. Together, the lexico-syntactic structures of modality, passivisation and nominalisation depict the developed world's responsibility as something desirable, not yet done.

\subsubsection{The Developed Countries' Attitudes towards Their Responsibility}

In both The Independent and The New York Times' reportage of the COPs, the developed world is represented as being worried, reluctant, indifferent, and even frustrated at their supposed responsibility for climate change. It is noteworthy that in almost all of the excerpts representing this attitude of the developed world, there are three language features that contribute to the qualities of impersonality of the discourse, namely lexical choices, passivisation and nominalisation. First, The Independent's lexical choices depicting the developed nations as being "reluctant to make big cuts," and "not act[ing] decisively enough and not [having] met their targets" (20 December 2009), wondering "how much money should the rich developed countries be prepared to offer the developing countries" (15 December 2009) help portray the rich developed countries' attitudes towards their responsibility. In fact, failure to act has increased on the part of the developed world. There is just "a promise to mobilise a climate fund by 2020." The developed countries are even represented with their shameful behaviour.

Excerpt 5: Murray Worthy, the organization policy officer, said: "Developed countries have behaved shamefully, blocking meaningful progress on tackling climate change.

They have refused to acknowledge their historical responsibility for the crisis, either by agreeing to reduce their emissions or by providing finance to help developing countries deal with climate change." (The Independent, 11 December 2011; emphasis added)

The shameful behaviour and refusal to acknowledge their responsibility indicate the developed countries' tendency of not taking responsibility. As detected from The Independent corpus, due to the "binding international targets place the heaviest burden on developed countries" (18 November 2007), "developed countries are reluctant to make big cuts unless developing countries do too" (06 December 2009). Particularly,

Excerpt 6: The developed countries, on the other hand [...] wanted to tear up Kyoto and replace it with a new deal, to set legally binding targets on the developing world alongside those on the rich nations. (The Independent, 29 November 2010; emphasis added)

The heavily emotionally loaded verb "tear up" picturesquely describes the developed world's attitude and preferred course of action against the Kyoto protocol, which has not been favoured by the developed countries due to their responsibility stated therein. Obviously, the developed countries do not want to work on climate change alone, but together with the developing countries. The Independent now sways to neoliberal ideology and requires every country to shoulder the socially shared responsibility, presenting a decline in the UK's commitment to climate change.

Second, beside the above-mentioned lexical choices, the passivisation of developed countries seems to depict a situation in which the developed countries do not intrinsically feel their responsibility for climate change issues. For example, the passivisation of the developed countries in "an agreement on 50 per cent reductions in global emissions by 2050 , or on 80 per cent reductions by developed countries" and in "developed countries are called on to step up their emissions cuts and their pledges of financing to help poor countries" (The Independent, 2013) showcases that the Kyoto protocol is not put forward by the developed nations themselves. Hence, they will not necessarily agree on and act in accordance with the protocol or take responsibility.

Third, nominalisation is used to veil the agents of the actions. For example, in "hardly anything is spent in the poor world" and "little attention is being given to the costs to poor countries of climatic changes," the agents of "spending" and "given attention" are actually the developed nations. Moreover, when mentioning the very small money that the UN climate fund receives ("less than $34 \mathrm{~m}$ "), it is not clearly stated who provides the money to the fund. Obfuscated by nominalisation, the developed countries don't appear to do anything as they should for the climate change issues. The Independent's elements of impersonal style (Fairclough, 1995), namely passivisation and nominalisation, seem to direct the reader's attention to the process, or the status quo, rather than the agent (who is responsible); hence, the role of the developed world is mystified.

In The New York Times, the developed countries are represented with the lexical choices of "have not done more" (07 November 2006), "be less willing to make the financial investments in climate change" (12 December 2008), "their proposals to help the poor countries combat climate change generally fell on deaf ears" (2008), "refuse to 
consider seriously," "agree only reluctantly to add loss and damage to the agenda" (20 November 2013), and "fear." For instance:

Excerpt 7: Developed nations fear footing the bill for potentially unlimited future liability and agreed only reluctantly to add loss and damage to the Warsaw agenda at the end of last year's climate conference in Doha, Qatar. (The New York Times, 20 November 2013; emphasis added)

Even worse, the developed countries are represented with a fairly strong verbal process in "having refused to acknowledge their historical responsibility for the crisis" (The New York Times, December 2011), which is intertextual with The Independent's article (see Excerpt 5). This negative attitude even amplifies into a seriously negative act of "bullying."

Excerpt 8: Britain and other rich countries are using aid money as a lever to bully developing countries over climate change, according to a new report by an anti-poverty pressure group....the World Development Movement, said: "The US, UK and EU are using the same strong-arm tactics to bribe developing countries that we saw at Copenhagen." (The New York Times, 27 November 2011; emphasis added)

According to Collins Cobuild Online Dictionary (Note 2), the verb "bully" is defined as "to hurt, intimidate, or persecute (a weaker or smaller person), especially to make him or her do something." In this representation, the rich countries are personified as someone stronger or bigger, while the developing countries weaker or smaller. In this asymmetrical relation, the developed countries are in a position of using their strength or power (to be precise, using their aid money) as a means of exerting pressure on the developing ones. Additionally, the war metaphor "strong-arm tactics" emphasises the developed countries' power over the developing ones at the climate conferences. Thus, the language used in this excerpt and other concordance lines representing "developed countries" in The New York Times corpus shows that the developed countries are driving the developing ones to accept their way of doing, and finally, to skew the climate conferences in the developed world's favour. This finding confirms Cannon \& Muller-Mahn's (2010, p. 11) argument that "discourses are constituted by groups of actors who are linked by controversies, and who try to gain superiority over the other participants in a particular discourse by pushing or even forcing the others to accept their position."

It is found in The New York Times' corpus that the reasons for the developed countries' irresponsibility, reluctance, indifference, even frustration, are economic. In 2005, "high unemployment" and "energy shortages" are cited as excuses for their unwillingness to sacrifice economy in order to meet the emissions targets. The developed countries are more concerned about maintaining their economic competitive edge. If they cut emissions too fast, their economies might be negatively influenced. Then, "global recession" and "it is the private money" are given as other excuses at COP14 and COP15, respectively. It is stated that the major reason for the United States to refuse binding emissions targets is its economic concern:

Excerpt 9: And the United States - by far the world's largest producer of greenhouse gases - continues to say that emissions targets or requirements would stunt economic growth in both rich and poor nations. (The New York Times, 04 December 2005; emphasis added)

It is implied that meeting emissions targets would impede the development of not only the rich countries but also of the poor ones' economies. By focusing on the negative impact of the emissions requirements on economies, the newspaper seems to advocate for not meeting emissions requirements. This finding is in line with McComas \& Shanahan's (1999) study that the coverage of climate change has now tended to centre on economic and international themes, rather than the scientific issue of climate change itself.

Besides, it is explained in the developed countries' fear of letting fast-growing countries free of obligations on gases emissions cuts. For instance:

Excerpt 10: Western governments, which in some cases are already starting to consider their own adaptations to climate change, agree in principle that they should help poor countries. But they have committed relatively small sums, and they are wary of letting fast-growing countries like China off the hook on emissions. Analysts say the likeliest outcome of the Warsaw negotiations is a weak pact that essentially urges countries to do what they can to cut emissions. (The New York Times, 11 November 2013; emphasis added)

The fast-growing countries actually emit lots of gases during their development process, so the rich countries want them to be obliged to cut emissions alongside the rich ones. In particular, developed nations are more worried about the economic impact of changing the fundamental underpinnings of their economies than about the emissions commitments or the financial aid to poor countries. The use of these reasons can be perceived as a 
discursive strategy to manipulate the reader to consider the effects on the economy so as to distract their concern about the developed countries' responsibility for climate change. In this way, The New York Times' journalistic norms facilitate the developed countries' ideologies and the status quo, diverting the reader's attention from the genuine issue of countries' responsibilities for climate change (Boykoff \& Roberts, 2007).

As a result, the COP19 in 2013 is predicted to end with a decision that "countries do what they can to cut emissions," no matter which countries they are. In this manner, the newspaper signals a reorientation of the climate change regime. Rather than working with a top-down approach of Kyoto protocol through the COPs, a bottom-up approach is now advocated, whereby each country can define its own national emission reductions and decide itself on its appropriate emission reduction targets, schedule and actions (Koch, König, Sanden, \& Verheyen, 2012).

In brief, the lexical choice, passivisation, nominalisation, modality, and metaphor in the corpora have been manoeuvred by the newspapers to obfuscate the developed countries' responsibility for the global climate issues, calling the developing countries to share the responsibility for climate change, and paving the way for the developed countries' delayed action against climate change. In this manner, the media discourse helps the developed countries pertain to their superior power and convey the message underpinning the developed countries' ideological stances.

\subsection{The Developing Countries}

\subsubsection{The Developing Countries' Responsibility for Climate Change (Note 3)}

In the sample concordances of "developed countries" in The New York Times corpus, such words as "similar," "likewise," "along with" are used in collocation with obligation modalities "should be obligated," "must," "requiring" so as to indicate the developed world's requirement that [major] developing countries act along with the developed countries by reducing their carbon emissions in their development process. These obligation modalities are articulated by the developed world's politicians, especially the US politicians. Such lexical choices and modalities seem to represent the developed world's authority in requiring the developing to take responsibility for climate change. For instance:

Excerpt 11: It [the White House] said, "The negotiations must proceed on the view that the problem of climate change cannot be adequately addressed through commitments for emissions cuts by developed countries alone. Major developing economies must likewise act." (The New York Times, 16 December 2007; emphasis added)

There seems to be a logical argumentation line developed by the thread of the modal verbs "must," "cannot," and the adverb "likewise" in this example. Due to the developed countries' inability ("cannot"), the obligation ("must") is on the major developing countries. Although the nominalisation ("the negotiations") renders a sense of vagueness about the actors at the global climate debate, it can be deduced from the context that there is a requirement that the countries at the climate conferences "proceed on the view" of the developed countries. The developed countries' ideological stance of requiring major developing countries to act is hidden when "the view" is naturalised by the media. In this manner of using language, the media may bolster the developed countries' ideology because "[i]deology is most effective when its workings are less visible [naturalised]" (Fairclough, 2015 , p. 208) to the consumer of the media text.

Mainly, it is advocated that the developed countries "alone" cannot solve the problem of climate change and (major) developing countries are called upon to take action. This advocation can be explained by the social context in which, according to the UNFCCC Party Groupings, the US Congress has opposed to commitments for emissions reduction on its part and to any international treaties that exclude developing countries. The US Senate has even passed the Byrd-Hagel resolution which blocks ratification of any agreement that commits the US to reducing emissions without commitments for developing countries or harms the US economy. This political stance is well instilled in the newspaper's discursive practice.

In The New York Times' concordances of "developing countries," the responsibility desired or required of the developing countries are expressed through the modalities "would need," "unless," "must," which complement the verbs "pledge" and "commit," such as in the excerpts below.

Excerpt 12: But this new framework needs to include the developing countries, including China and India, who are not obliged to accept targets but have a key role to play; also the United States, the world's largest economy. (The New York Times, 17 November 2005; emphasis added)

Excerpt 13: Today Mr. Miliband said a global deal would need commitments from developed countries to cut emissions, pledges from developing nations to move away from "business as usual" greenhouse gas 
output and funding for poorer countries to cope with climate change and cut their emissions. (The New York Times, 02 December 2008; emphasis added)

Excerpt 14: ...developed countries reluctant to make big cuts unless developing countries do too. (The New York Times, 06 December 2009; emphasis added)

With the reiteration of such lexical choices as "key" and "largest," the newspaper highlights the importance of the major developing countries, particularly China and India, in the new global climate framework. The combination of the lack of obligation ("are not obliged") and the emphasis on these countries' importance raises a matter of concern, that is, the major developing countries have key roles to play in the fight against climate change. Also, three things are found to be expected of the developing countries as their responsibility for climate-related problems, namely (1) move away from "business as usual," (2) fund poorer countries, and (3) cut their emissions.

Moreover, it is found in The New York Times' representation of the rich countries that it is important to set up a new protocol. For example,

Excerpt 15: The parties agreed last year in Durban, South Africa, to work toward a new protocol or other legally binding instrument that would require actions of all parties, not just rich countries as under the Kyoto agreement of 1997. (The New York Times, 09 December 2012; emphasis added)

It is implicitly conveyed that the developing countries need to be included in the new global climate treaty. Overall, the developing world is required to work with the developed world in dealing with the global climate problems.

Two main reasons are found in The New York Times corpus, namely (1) climate change is a threat to the developing countries and they, therefore, should take responsibility for themselves, and (2) the developing countries are increasingly emitting greenhouse gases into the atmosphere and should take their responsibility for climate change. First, the media equate climate change with "life and death," "threat," (for instance, "[i]n the developing world climate change is about life and death" (2005), "[f]or the developing world, climate change is not a future threat, but a contemporary crisis" (2009)), picturing it at the present, not in the future, time. Therefore, it brings a more immediate need to the developing countries to act against climate change and makes it more real to the reader. Second, The New York Times focuses on the developing countries' rapid economic growth and drills on these countries' rising contribution of greenhouse gases in the atmosphere through the reiteration of "rapidly," "biggest," "huge," etc. Other reasons for the developing world to take action include they "have a key role to play" (2005), they "have no caps under Kyoto" (2007), "rapidly catching up" (10 December 2008), "about 90 per cent of future emissions growth would come from the developing world," "the biggest carbon emitters," "now huge CO2 emitters" (15 December 2009), "carbon emissions have soared" (20 December 2009), and due to "their rapidly rising CO2 emissions" (2009). By emphasising the developing countries' level of gas emissions, the newspaper might invoke the reader into considering the developing countries' responsibility for climate change corresponding to this level. The argumentation line of focusing on the developing countries' rising power thanks to their rapid economic growth is deployed in support of the developed countries' requirement that developing countries take responsibility for climate-related problems along with themselves. Again, the UNFCCC conferences are fudged so that the newspapers' coverage of the COPs result in the outcomes that are politically acceptable for the developed countries.

In The Independent's concordances of "developing countries," the requirements for the developing countries to take responsibility for climate change are also observed. The developing countries, particularly China, India, and Brazil, are required "to agree to their own emissions targets," "to agree to join the battle against the climate change," "to do something in terms of reducing their emissions," to make "pledges to move away from "business as usual" greenhouse gas output" (02 December 2008), "to commit to taking action" (06 December 2009), and "to take actions of their own to reduce emissions." Although it is not always explicitly stated that the developed countries require the developing countries to do so, their authority is conveyed via the syntactic structures of "get leading developing countries to agree," "have to do," and "require developing countries to take actions." Thus, the entanglement of different ideologies in the discourse under study is detected here. That is, the ideology about the developed world's superior power to get the developing world to take action is entangled with the ideology about the developing countries' responsibility for climate change.

In brief, the modalities and syntactic structures were employed in the media discourse to construct the ideology about the requirement for the developing countries to take charge of climate-related issues. It is reaffirmed here that modalities may help the media convince or even manipulate the reader's mind in ways that the ideology conveyed through such language features becomes natural and acceptable to the reader. 


\subsubsection{The Developing Countries' Attitudes towards Their Responsibility}

It is detected in the corpora that the two newspapers under study represent quite different attitudes of the developing countries to their supposed responsibility for climate change. In the first few years under study, The New York Times describes the developing countries' taking action.

Excerpt 16: But the developing countries have already taken far-reaching domestic action to cut pollution and develop renewable energy and were expressing their willingness in Montreal's corridors last week to "play their part." (The New York Times, 04 December 2005; emphasis added)

As is depicted in the above excerpt, the developing countries are responsible by taking "far-reaching domestic action." As far as climate change is concerned, the action at the national, or domestic, level can contribute to the reduction of the global-scale pollution. Though the developing countries' willingness to take action is represented with the verbal process of "express," it is a positive sign of their attitude towards the responsibility for climate change.

However, in the later years under study, The New York Times becomes less outspoken of the developing nations' "willingness" to take responsibility. Instead, it tends to resort to modalities to convey obligation (e.g., "developing countries must also commit to taking action") and desirability (e.g., "would need commitments from") for the responsibility to be shared by the developing countries. Also, the Copenhagen accord is quoted to "formally engage[s] the developing countries to do something about their rapidly rising CO2 emissions" (2009).

On the contrary to The New York Times' depiction, it is found in The Independent corpus that the developing world declines the responsibility. Despite the immediate challenge of climate change as well as the hard pressure from the developed world, the developing countries have by far been trying to insist that the developed countries take initial actions and to resist taking responsibility for binding emissions targets. Consider the reason for this rejection, as advocated by a China's official.

Excerpt 17: China's chief climate negotiator, Xie Zhenhua, recently said China's emissions could peak when its per capita gross domestic product reaches roughly half of what it was when developed countries' emissions peaked. (The Independent, 27 November 2012; emphasis added)

By comparing the future of China's (a developing country's) level of emissions in terms of GDP with the past of developed countries' level, the newspaper's quotation of the Chinese official's statement shows the big difference between the greenhouse gas emissions levels of the two parts of the world at the present time. This is, therefore, a plausible counter-argument to the developed countries' reasoning that fast-growing countries, including China, have to take charge of climate change due to their currently increasing emissions. In the long run, it is reasonable for the latter to resist any commitment to emissions reductions.

This difference between the two newspapers' depictions of the developing countries' attitudes towards their supposed responsibility for climate change can be explained by the discursive and socio-economic contexts embedding the discourse under study. While The Independent hardly mentions the trading relation between the UK, other developed countries and developing countries, The New York Times does address the trading relationship between the US, other developed countries and China. For instance:

Excerpt 18: We know where most of those Chinese exports are headed-to developed countries, like the United States, which accounts for about a quarter of them. A rough calculation suggests that almost 6 percent of Chinese carbon emissions are generated in the production of goods consumed here. (The New York Times, 16 December 2007; emphasis added)

There is an economic tie between the United States and China, from which both nations benefit. The underlying reason is that, as the US imports goods mainly from China, the US will have to pay extra money to Chinese producers once the carbon emissions reduction targets are exerted on the Chinese products. Both of them, hence, never want any binding targets on the Chinese goods exported to the US.

In brief, the news coverage of the global climate conferences is influenced by the media's discursive practices, which in turn are influenced by the broader socio-economic circumstances that embedded the COPs. While the developing countries' responsibility for climate change is more clearly articulated in The New York Times throughout the study period, it is not so vividly depicted in The Independent. These different representations are shaped by the two newspapers' different ideological commitments. To a certain extent, they are shaped by the high-level power relation between countries, whereby the US seeks convergent economic benefits with China whereas the UK seems dim on this relation with the developing world. Therefore, "they do shape social life in all its manifold aspects" (Fairclough, 2015, p. 28). 
All things considered, the use of language by the newspapers has a social power in shaping the public understanding of climate conferences and in the advancement or impediment of social change in the long run. They advance the social change in which the Kyoto protocol, which is not in the developed countries' favour, should be replaced by a new global climate treaty, requiring the developing countries to act along with the developed ones. In the mean time, the media imped the social change in the global power configuration in that they contribute to sustain the ideologies about the countries' responsibilities in the interest of the developed nations. By constructing the developed and developing countries at the global climate conferences in ways that justify and promote preferred courses of action, the newspapers tended to construct readers' mental models or representations of the countries' responsibilities as well as to influence the way readers think and feel about the developed and developing countries' responsibilities, thus consequently behave or act towards the issues of climate change in the long run. Therefore, they discursively "construct fields of action and fields of inaction" (Carvalho, 2007, p. 238).

\section{Conclusion}

This study has achieved three main goals: a practical goal, a methodological goal, and an educational goal. First, it decoded the ideologies about the developed and developing countries' responsibilities for climate change as conveyed through The Independent and The New York Times' coverage of the global climate conferences, investigated the language used in conveying these ideologies, and explained why the language was used the way it was in the discourse. In so doing, the study results contributed to a greater understanding of the media's ideologies about the countries' responsibilities for climate change. Second, it contributes to the existing body of research which applies corpus-assisted CDA in research on climate change issues. Third, it enhances understanding of the significance of CDA in education and media.

Linguistically, the lexical choice, passivisation, nominalisation, modality, and metaphor were ideologically invested in the discourse to represent the developed and developing countries and to legitimise the developed countries' positions on their responsibility for climate change. Discursively, the newspapers' ideological stances were well reflected in the way they represented the countries at the conferences. On balance, the research results showed that the linguistic features, discursive practices and social factors were entangled in the discourse, constituting the newspapers' ideologies and shaping the reader's understanding of the countries' responsibilities for climate change as well as of the international climate conferences.

Future research may examine the media discourse at a greater depth across the wider strata of newspapers, or analyse different types of texts to investigate the intertextuality in discourses on climate change. Moreover, it is important to examine how new developments in cultural, economic, social and political spheres affect the COPs in particular and global climate change in general.

\section{References}

Boykoff, M. (2008). The cultural politics of climate change discourse in UK tabloids. Political Geography, 27, 549-569. https://doi.org/10.1016/j.polgeo.2008.05.002

Boykoff, M. T., \& Boykoff, J. M. (2004). Balance as bias: global warming and the US prestige press. Global Environmental Change, 14, 125-136. https://doi.org/10.1016/j.gloenvcha.2003.10.001

Boykoff, M. T., \& Roberts, J. T. (2007). Media coverage of climate change: current trends, strengths, weaknesses: United Nations Development Programme.

Caillaud, S., Kalampalikis, N., \& Flick, U. (2012). The Social Representations of the Bali Climate Conference in the French and German Media. Journal of Community and Applied Social Psychology, 22, 363-378. https://doi.org/10.1002/casp.1117

Cannon, T., \& Mueller-Mahn, D. (2010). Vulnerability, resilience and development discourses in context of climate change. Natural Hazards.

Carvalho, A. (2005). Representing the Politics of the Greenhouse Effect: Discursive Strategies in the British Media, Critical Discourse Studies, 2(1), 1-29. http://dx.doi.org/10.1080/17405900500052143

Carvalho, A. (2007). Ideological cultures and media discourses on scientific knowledge: re-reading news on climate change. Public Understanding of Science, 16, 223-243. https://doi.org/10.1177/0963662506066775

Carvalho, A., \& Burgess, J. (2005). Cultural circuits of climate change in UK broadsheet newspapers, 1985-2003. Risk Analysis, 25(6), 1457-1469. https://doi.org/10.1111/j.1539-6924.2005.00692.x

Carvalho, A., \& Pereira, E. (2008). Communicating climate change in Portugal: A critical analysis of journalism and beyond. In A. Carvalho (Ed.), Communicating Climate Change: Discourses, Mediations and Perceptions. 
Braga: Universidade do Minho.

Chouliaraki, L. (1999). Media discourse and national identity: death and myth in a news broadcast. In R. Wodak \& C. Ludwig (Eds.), Challenges in a Changing World: Issues in Critical Discourse Analysis (pp. 37-62). Passagen, Vienna.

Collins Cobuild Online Dictionary. Retrieved from https://www.collinsdictionary.com/dictionary/english

Dispensa, J. M., \& Brulle, R. J. (2003). Media's social construction of environmental issues: Focus on global warming - a comparative study. Science Communication, 35(3), 334-357. https://doi.org/10.1108/01443330310790327

Dryzek, J. (2005). The Politics of the Earth: Environmental Discourses. Oxford: Oxford University Press.

Fairclough, N. (1989). Language and Power. London: Longman.

Fairclough, N. (1995). Critical discourse analysis. The critical study of language. London: Longman.

Fairclough, N. (2000). New Labour, New Language? London: Routledge.

Fairclough, N. (2005). Peripheral Vision-Discourse Analysis in Organization Studies: The Case of Critical Realism. Organization Studies, 26(6), 915-939. https://doi.org/10.1177/0170840605054610

Fairclough, N. (2015). Language and Power (3rd ed.). London: Longman.

Fairclough, N., \& Wodak, R. (1997). Critical discourse analysis. In T. van Dijk (Ed.), Discourse as Social Interaction —Discourse Studies: A Multidisciplinary Introduction (Vol. 2, pp. 258-284). London: Sage.

Fløttum, K., \& Gjerstad, Ø. (2017). Narratives in climate change discourse. WIREs Climate Change, 8: n/a, e429.

Gentzkow, M., \& Shapiro, J. M. (2010). What Drives Media Slant? Evidence from U.S. Daily Newspapers. Econometrica, 78(1), 35-71. https://doi.org/10.3982/ECTA7195

Gillard, R. (2016). Unravelling the United Kingdom's climate policy consensus: The power of ideas, discourse and institutions. Global Environmental Change, 40(2016), 26-36. https://doi.org/10.1016/j.gloenvcha.2016.06.012

Grundmann, R., \& Krishnamurthy, R. (2010). The discourse of climate change: A corpus-based approach. Critical Approaches to Discourse Analysis across Disciplines, 4(2), 125-146.

Koch, H. J., König, D., Sanden, J., \& Verheyen, R. (2012). Climate Change and Environmental Hazards Related to Shipping: An International Legal Framework: Proceedings of the Hamburg International Environmental Law Conference 2011. Leiden: M. Nijhoff Publishers.

Lillian, D. L. (2008). Modality, Persuasion and Manipulation in Canadian Conservative Discourse. Critical Approaches to Discourse Analysis across Disciplines, 2(1), 1-16.

McComas, K., \& Shanahan, J. (1999). Telling Stories About Global Climate Change: Measuring the Impact of Narratives on Issue Cycles. Communication Research, 26(1), 30-57. https://doi.org/10.1177/009365099026001003

Moser, S. C., \& Dilling, L. (2007). Creating a Climate for Change: Communicating Climate Change and Facilitating Social Change. Cambridge, UK: Cambridge University Press. https://doi.org/10.1017/CBO9780511535871

Nerlich, B., Evans, V., \& Koteyko, N. (2011). Low carbon diet: Reducing the complexities of climate change to human scale. Language and Cognition, 3(1), 45-82. https://doi.org/10.1515/langcog.2011.003

Parks, B., \& Roberts J. T. (2010). Climate Change, Social Theory and Justice. Theory, Culture \& Society, 27(2-3), 134-166. https://doi.org/10.1177/0263276409359018

Penetrante, A. M. (2010). Politics of Equity and Justice in Climate Change Negotiations in North-South Relations. In H. G. Brauch, U. Spring, C. Mesjasz, J. Grin, P. Kameri-Mbote, B. Chourou, ... J. Birkmann (Eds.), Coping with Global Environmental Change, Disasters and Security-Threats, Challenges, Vulnerabilities and Risks (Vol. 5, pp. 1355-1366). Berlin, Heidelberg \& New York: Hexagon Springer-Verlag.

Richardson, J. E. (2007). Analysing newspapers: an approach from critical discourse analysis. New York: Palgrave Macmillan. https://doi.org/10.1007/978-0-230-20968-8

Scott, M. (2012). WordSmith Tools version 6. Liverpool: Lexical Analysis Software.

Thaker, J., \& Leiserowitz, A. (2014). Shifting discourses of climate change in India. Climatic Change. 
https://doi.org/10.1007/s10584-014-1059-6

Trumbo, C. (1996). Constructing climate change: claims and frames in US news coverage of an environmental issue. Public Understanding of Science, 5(3), 269-283. https://doi.org/10.1088/0963-6625/5/3/006

Ukonu, M. O., Akpan, C. S., \& Anorue, L. I. (2013). The Media and the Contradictions in Commitments to the Fight against climate change. Afrrevjo International Journal of Arts and Humanities, 2(1), 1-16.

United Nations. (1998). Kyoto Protocol to the United Nations Framework Convention on Climate Change.

van Dijk, T. A. (1998). Ideology. A multidisciplinary approach. London: Sage.

van Dijk, T. A. (2001). Critical discourse analysis. In D. Schiffrin, P. Tanne \& H. Hamilton (Eds.), The handbook of discourse analysis (pp. 352-371). Malden, MA: Blackwell.

Wang, F. (2009). A Corpus-based Discourse Analysis of Global Warming in British, American and Chinese newspapers. In M. Mahlberg, V. González-Díaz, \& C. Smith (Eds.), Proceedings of the Corpus Linguistics Conference CL2009. University of Liverpool, UK. Retrieved from http://ucrel.lancs.ac.uk/publications/cl2009/

Weingart, P., Engels, A., \& Pansgrau, P. (2000). Risks of communication: discourse on climate change in science, politics and the mass media. Public Understanding of Science, 9, 261-283. https://doi.org/10.1088/0963-6625/9/3/304

Wodak, R., \& Meyer, M. (Eds.). (2012). Methods of critical discourse analysis. London: Sage.

\section{Notes}

Note 1. The Kyoto Protocol is an international agreement developed by the United Nations. It was adopted unanimously in 1997 and entered into force on 16 February 2005. The Protocol's major feature is that it has mandatory targets on greenhouse-gas emissions for the world's leading economies which have accepted it.

Note 2. According to Collins Cobuild Online Dictionary. Retrieved fromhttps://www.collinsdictionary.com/dictionary/english/bully

Note 3. It is noteable that the developing countries' responsibility for climate change is mainly detected from The New York Times corpus throughout the study period while in The Independent only in the later years. This is the reason for the shorter length of section 4.2 in comparison with section 4.1 .

\section{Copyrights}

Copyright for this article is retained by the author(s), with first publication rights granted to the journal.

This is an open-access article distributed under the terms and conditions of the Creative Commons Attribution license (http://creativecommons.org/licenses/by/4.0/). 